\title{
Social Dominance Orientation Predicts Civil and Military Intelligence Analysts' Utilitarian Responses to Ethics-of-Intelligence Dilemmas
}

\author{
Francesco Margoni ${ }^{1}$ and Giangiuseppe Pili ${ }^{2}$ \\ ${ }^{1}$ Department of Psychology, University of Oslo \\ ${ }^{2}$ Intelligence Lab, University of Calabria
}

This is a pre-print version of the work.

\begin{abstract}
Authors note
Francesco Margoni ORCID ID https://orcid.org/0000-0002-8109-228X

Giangiuseppe Pili ORCID ID https://orcid.org/0000-0002-7360-6826

Correspondence should be addressed to Francesco Margoni, Department of Psychology, University of Oslo, Forskningsveien 3A, 0373 Oslo, Norway (e-mail: francesco.margoni@gmail.com), or to Giangiuseppe Pili, Intelligence Lab, University of Calabria (e-mail: giangiuseppe.pili@socint.org).
\end{abstract}




\begin{abstract}
What is the real ethical framework of an intelligence analyst? We addressed this question by presenting a group of civil and military intelligence analysts with a set of dilemmas depicting intelligence agents facing the decision about whether to violate a deontological rule where that would benefit their work. Participants judged how much violating the rule was acceptable. Next, we measured participants' individual differences in social dominance orientation (the proclivity to endorse intergroup hierarchy and anti-egalitarianism), their deontological and utilitarian tendencies (using classical moral dilemmas), and how much they value rule conformity, traditions, and safety and stability in the society. Among these factors, only social dominance significantly helped explain variability in participants' resolution of the ethics-of-intelligence dilemmas. Specifically, social dominance positively predicted the tendency to judge violating the deontological rule acceptable. For the first time in the open literature, we elucidated some key aspects of the real ethics of intelligence.
\end{abstract} Keywords: intelligence, military intelligence, social dominance, morality, utilitarianism. 


\section{Social Dominance Orientation Predicts Civil and Military Intelligence Analysts' Utilitarian Responses to Ethics-of-Intelligence Dilemmas}

Societies, institutions, and political organizations constantly face threats to their own security. These can be posed by other societies, states, or terrorist organizations. Civil and military intelligence functions pursued by appropriate agencies are meant to fight back and protect from hostile countries, organizations or individuals (Goldman, 2006). Specifically, intelligence is aimed to foresee enemy's intentions, behavior and capability (Gill \& Phythian, 2012, 2016; Horn, 2003; Pili, 2019; Warner, 2002). The intelligence outcome is forwarded to the decision makers to inform them about the enemy. Thus, intelligence analysts work to produce analyses and assessments of different facts on the ground from geopolitical scenarios to technical evaluations (e.g. nuclear explosions, missile tests, piracy activity). They seek to process the gathered information into an intelligence product, which is a particular kind of informational product. The main aim of professionals is to collect information and produce relevant and strategic knowledge to ground a rational decision by the decision makers.

However, whereas this knowledge is often meant for the public benefit, the ordinary citizen cannot have access to it. Indeed, intelligence is secret in at least two fundamental ways: its process is secret as it is its outcome (Pili, 2019). Moreover, intelligence can be regarded as a particularly valuable source of information because it can prevent harm to citizens but also because, if disclosed, can sometimes return a more truthful version of the facts (historical facts for instance). We can further consider that intelligence analysts are citizens too and sometimes have duties whose fulfillment may come into conflict with their 
deontology as analysts. For instance, they can be researchers in academia, students or professors, interested in disseminating knowledge to a large audience in the open literature.

These few facts can already generate ethical dilemmas that intelligence professionals may have to deal with. Consider for example that intelligence professionals have certain deontological duties that, if unfulfilled, can cause extreme personal and professional consequences. With respect to the treatment of classified information and leaked documents, they sometimes can be students enrolled in University courses, professors and academic researchers (Goldman, 2018). Within this scenario, it is possible to ask to what extent they should adhere to deontology instead of prioritizing their duties as citizen-students or academics. $^{1}$

Let us imagine that a former intelligence professional deployed in Vietnam during the war is now an academic hired in a University, and she is asked to prepare a course and publish a paper presenting the history of intelligence in Vietnam. Imagine that she realizes that the open sources do not fully cover some crucial facts that she instead is aware of because of her past activity. To what extent shall this person use classified information in her possession to properly cover her duties as an academic and make a truthful and meaningful explanation of what happened during the war? With this example, we can appreciate how sometimes deontological concerns (e.g., classified information should not be

\footnotetext{
${ }^{1}$ At the same time, the most dangerous possibility is that the intelligence professional breaks the oath to pursue their own interest. Though betrayal is definitely the worst offence, this is not something we considered in our study because it would have meant depicting the analysts as traitors, which was an option beyond our experiment. However, this would be an extremely important topic to explore because it is likely that the agencies already inquired over the conditions that trigger the worst possible damage and offence. However, as far as we know, this is still something specific to each agency and not released to the open research.
} 
publicly available) conflict with concerns for the benefit of the state (e.g., using relevant information would offer to the ordinary citizen a more truthful version of what really happened in Vietnam).

The benefit of violating the professional ethics can also be for the purposes of the intelligence mission itself. Let us imagine an intelligence analyst working for a U.S. agency who is unable to retrieve a relevant piece of information from the Intelligence Community. It would turn out to be precious to solve his problem. This information is actually leaked and released in a neo-Wikileaks, and he can easily access it from his laptop at home. Should he use the leaked information, knowing that such a practice would not be allowed and even be punishable by the law? In a way, in this, as in other cases, we have a dilemma. This dilemma can be solved either in favor of strictly respecting the deontological rules of the analyst profession or in favor of a more utilitarian reasoning that would lead to violate the deontological rule to eventually serve the state (e.g. by disseminating truthful information or more efficiently protecting from threats to national security).

In the current study, for the first $\operatorname{time}^{2}$ we investigated how real intelligence professionals, and a control group of non-professionals, evaluated acts that would violate a deontological rule of the analyst profession but, at the same time, potentially benefit the state, by either favoring the success of a mission (and thus increase national security, for instance) or fulfilling duties of dissemination as academics and researchers. We presented participants with dilemmatic scenarios (henceforth, ethics-of-intelligence dilemmas) depicting intelligence agents having to decide about whether to act and violate a

\footnotetext{
${ }^{2}$ At least in the open literature.
} 
deontological rule of their profession. Violating the rule would result in benefiting their work as either intelligence analysts or academics (e.g., using leaked information to produce intelligence, or classified information in their work as academics). The second aim of our study was to investigate which factors can help explain or predict individual differences in the analysts' evaluations of the ethics-of-intelligence dilemmas.

The Social Dominance Orientation was the first possible predictor we considered (SDO; Pratto et al., 1994). It is defined as "the general desire to establish and maintain hierarchically structured intergroup relations regardless of the position of one's own group(s) within this hierarchy” (Sidanius et al., 2016, p. 152; see also Kleppest $\varnothing$ et al., 2020). At the individual level, SDO can be measured by a scale consisting in 16 statements, such as "Inferior groups should stay in their place" (Ho et al., 2015). Participants specify their level of agreement or disagreement with these statements. SDO scale measures the extent that one endorses both group-based social hierarchy and anti-egalitarianism (i.e. preference for inequality or opposition toward reducing inequality). Research has reported that SDO is a robust predictor of intergroup attitudes including political and economic conservatism (Dunwoody \& McFarland, 2018; Sidanius \& Pratto, 1999; see also Sheehy-Skeffington \& Thomsen, 2020) and prejudice against minorities or low status groups (Sidanius et al., 2016; Thomsen et al., 2008).

In general, SDO has been found to predict intergroup attitudes that enhance rather than reduce disparities between social groups in favor of the dominant groups and the existing hierarchical status quo, where high SDO individuals tend to think that society is a competitive place, where everyone fights for power, and high status groups need to defend themselves from threats posed by subordinates groups (Pratto et al., 2006; Sidanius et al., 
2016; Thomsen et al., 2010). Especially when individuals are members of the dominant group, SDO can be strongly related to ingroup favoritism. Here we predicted that intelligence analysts high in SDO will show a greater tendency to endorse utilitarian responses to the ethics-of-intelligence dilemmas (indeed, there is initial evidence suggesting that higher scores in SDO are associated with a decreased preference for deontological resolutions; Bostyn et al., 2016). In these individuals, the need to protect the state or a company against threats posed by outgroup organizations or better serve the state or the company by disseminating useful knowledge, may be weighed more than the need to respect deontological rules of their profession. In our predictions, then, leniency in judging the violation of deontological rules would be in part explained by individual differences in SDO.

Next, individual differences in the importance given to safety and stability in the society (e.g., the fact that the country protect itself against all possible threats), cultural, family or religious traditions, and conformity to rules, laws and authority were measured (we used the Value Survey developed by Schwartz et al., 2012). We reasoned that analysts who weigh more safety and stability in the society, as well as those who defend the importance of respecting the existing hierarchical status quo (either traditions or authority), would tend to endorse a utilitarian resolution to the dilemmas. Again, this can be so because violating a deontological rule may be deemed appropriate if ingroup identity and security are in danger, they are judged as particularly valuable, and violating the rule can benefit society. However, a different possibility is that higher scores in conformity to rules and authority would lead participants to endorse a deontological resolution, i.e. compliance with rules no matter what. Lastly, since we characterized ethics-of-intelligence dilemmas as eliciting either a deontological or a utilitarian response, we also measured participants' tendency to give 
utilitarian rather than deontological solutions to classical moral dilemmas such as killing one person to save five (Greene et al., 2001; Patil et al., 2020). In particular, the process dissociation approach that allows to assess the strength of both utilitarian and deontological inclinations in participants' moral decision making was employed (Conway \& Gawronski, 2013). We predicted that both these inclinations would be useful in explaining part of the variability in participants' resolutions of the ethics-of-intelligence dilemmas.

\section{Methods}

\section{Participants}

The sample size was determined by an a priori power analysis for the correlations between participants' evaluations of the ethics-of-intelligence dilemmas, participants' group (professionals, non-professionals), SDO scores and the other possible predictors (see Tables 1 and 2). To detect a medium effect size $\rho=0.30$ with alpha set at 0.05 , a power of 0.80 , point biserial model, two-tailed, a minimum total sample size of 82 participants was required.

Forty-one intelligence professionals $\left(M_{\text {Age }}=40.68\right.$ years, $S D=14.32$, age range 22-69; 9 female) and 41 non-professionals $\left(M_{\text {Age }}=40.73\right.$ years, $S D=13.89$, age range 24-72; 20 female) were recruited. Non-professionals had on average 18.27 years of school education, and were Europeans (21), North Americans (13), or Latin Americans (6). Analysts had on average 18.80 years of school education, and the majority of them were either Europeans (18) or North Americans (20). This geographical origin explains their regional expertise. Thus, we note that this study shows Western-world analysts' ethical reasoning, and it cannot be generalized to the rest of the world. After all, intelligence profession is shaped by political contexts, which are differentiated state by state and region by region. 
Intelligence professionals' main expertise was geopolitics (international politics and economic intelligence; 17), law enforcement (national security, counterintelligence and counterterrorism; 10), military intelligence (defense; 9), cyber intelligence (1), intelligence techniques (2), and other (2). They worked on average 11.03 years as analyst $(S D=11.27$, range 1-40), 27 of them in the public sector and 14 in the private sector. With respect to geographical expertise, we considered the main two regions for each participant in their own words: Middle East and North Africa (12), East Asia (11), Russia and post-Soviet countries (7), Europe (7), Latin America (6), Africa (4), North Africa (2), USA (2), Global (2), SubSaharan Africa (1), Central Africa (1), East Africa (1), South Pacific (1), Iran (1). Lastly, considering the kind of output professional participants have to deliver, the great majority of them reported that they have the duty to write down reports on the main subject matter of their expertise. Then, basically, if an analyst stated he/she works on counterintelligence, he/she is asked to write down reports.

\section{Materials and Procedure}

Participants completed an on-line survey which took approximately 30 minutes to be completed and was comprised of the measures listed above. The full survey can be accessed in the Supplementary Materials.

\section{Outcome Variable: Ethics-of-Intelligence Dilemmas}

Participants read and evaluated seven dilemmas where intelligence professional fictitious characters had to face the decision about whether to act and likely violate a deontological rule for the benefit of their work either as intelligence analysts or as University students/professors. After each dilemma, participants judged how much acting and violating the deontological rule was acceptable in their opinion, using a Likert scale anchored at 1 
with Not at all, at 4 with Somewhat, and at 7 with Very much. We also asked participants to briefly explain their answers (see the Supplementary Materials for a qualitative assessment of participants' explanations).

Dilemma 1 asked whether the story protagonist, a signal intelligence analyst for a U.S. Agency, being enrolled in a University course, should participate in a class discussion of a recently leaked document he contributed writing. Dilemma 2 asked whether the story protagonist, a former intelligence officer deployed in Vietnam during the war, now a postdoctoral scholar, should use classified evidence in her possession (historical facts about the war) to fulfill her research duties, i.e. writing a paper and preparing a course at the University. Dilemma 3 was a modified version of Dilemma 2, and asked whether the protagonist should use her prior knowledge of intelligence methods in the class.

Dilemma 4 asked whether the story protagonist, an intelligence analyst, should use at his job leaked information accessed at his home that he was unable to receive from the Intelligence Community. Dilemma 5 asked whether the story protagonist, an intelligence analyst who has a daughter whose boyfriend's family is active in drug and financial crimes, while investigating on the family should ask for information to her daughter without informing her about the investigation. Dilemma 6 was a modified version of Dilemma 5, and asked whether the mother should ask the daughter to spy knowing that the boy is actually innocent. Lastly, Dilemma 7 asked whether the story protagonist, a CIA agent who believes that there will be another major terrorist attack (9/11 magnitude), without having the legal permission, should spy even the private sexual life of a suspected informer of Al-Qaeda.

Dilemmas 1 and 4 were slightly modified versions of dilemmas developed by Goldman (2018). The remaining ones were developed mostly relying on the second author's 
experience as lecturer in Intelligence Analysis. Each dilemma was meant to elicit a conflict between a deontological resolution (i.e. the story protagonist should not act and, for instance, discuss or use leaked information) and a utilitarian resolution favoring the maximization of the outcomes (i.e. violating the deontological rule would likely benefit the story protagonist's work at the University, in Dilemmas 1-3, or increase the likelihood of success of his/her work as intelligence analyst, in Dilemmas 4-7).

Here a utilitarian resolution would immediately favor the research community and/or the welfare of the society at large. By contrast, a deontological resolution would likely be driven by concerns about rule compliance and the need to strictly adhere to deontology. Please note, however, that participants' responses can only be loosely defined as deontological or utilitarian. Indeed, a deontological resolution too could be driven by the reasoning that strictly adhering to the deontological ethics of the intelligence research and practice will result in favoring the society at large. Thus, we draw the distinction between utilitarian and deontological resolutions by keeping this important caveat in mind. Moreover, the use of these terms will refer mainly to the type of answer (utilitarian = the story protagonist should act; deontological $=$ the story protagonist should not act), thus will not refer to the in reality unknown motivations that led participants to the answer.

\section{Utilitarian vs. Deontological Responses}

We used the Process Dissociation (PD) approach outlined by Conway and Gawronski (2013) that, for each participant, allows to assess the strength of their utilitarian as well as deontological inclinations in moral decision making. PD relies on the comparison between incongruent dilemmas, where the two processes lead to different responses, and congruent dilemmas, where the two processes lead to the same response. Participants were thus 
presented with five pairs of incongruent and congruent classical moral dilemmas (selected among those developed by Conway and Gawronski, 2013). For instance, in its incongruent variant one dilemma asked participants to say whether it is appropriate to smother a child in order to save yourself and the other townspeople from being killed, whereas in its congruent variant it asked to say whether it is appropriate to do so to save yourself and the other townspeople from being captured by enemy soldiers. By comparing responses on incongruent variants to responses on congruent variants, one can dissociate the processes and obtain for each participant a score reflecting their tendency to endorse a utilitarian resolution and a score reflecting their tendency to endorse a deontological resolution.

\section{Social Dominance Orientation}

Participants were administered the Social Dominance Orientation scale (Pratto et al., 1994), a 16-item scale measuring individual preferences for hierarchy and inequality among social groups. For each item (e.g., "Some groups of people are just more worthy than others"), participants indicated the degree of their agreement using a 7-point Likert scale (1 $=$ Strongly disagree/disapprove, $7=$ Strongly agree/favor ). Higher scores indicate stronger levels of social dominance orientation.

\section{Value Survey: Security-Societal, Tradition, Conformity-Rules}

Participants were then presented with three subscales of the Value Survey (Schwartz et al., 2012) assessing the following 'values': security-societal, tradition, and conformity-rules. For each 'value', participants read three items and had to say how much the person in the description is or is not like them using a Likert scale ranging from 1 (completely not like me) to 7 (completely like me). Societal security emphasizes concerns for safety and stability in the society and state (e.g., "It is important to him/her that his/her country protect itself against 
all threats"). Tradition emphasizes attention for cultural, family or religious traditions (e.g., "It is important to him/her to maintain traditional values or beliefs"). Conformity to rules emphasizes compliance with rules, laws and authority (e.g., "He/she believes he/she should always do what people in authority say"). Items were presented in a randomized order.

\section{Political Conservatism}

Participants were asked to place their political views on a 12-point scale ranging from 1 (extremely liberal) to 12 (extremely conservative) (Feldman \& Stenner, 1997).

\section{Results}

\section{Preliminary Analyses}

There was a significant difference between the groups in terms of gender composition, $\chi^{2}(1, N=81)=6.08, p=.014, \phi=0.27$. However, since gender did not significantly predict participants' responses to the ethics-of-intelligence dilemmas, $\beta=-0.01, t(80)=-0.11, p=$ .909 , subsequent analyses omitted gender as a factor.

\section{Group Differences}

Table 1 reports means and 95\% CIs for all variables included in the current study separately for participants' group (analysts, control). ${ }^{3}$ A series of ANOVAs revealed that groups differed only in their tendency to give a utilitarian resolution to the ethics-ofintelligence dilemmas, $F(1,81)=9.57, p=.003$. On average, analysts gave more deontological responses compared to participants in the control group, overall judging that the story protagonist's action was between not at all and somewhat acceptable (see Table 1). No other between-group differences were found.

\footnotetext{
${ }^{3}$ The data are available from the corresponding author upon reasonable request.
} 


\section{Table 1}

Descriptive Statistics (Means, 95\% CIs, and Possible Range) for the Measured Variables for Analysts Participants and Participants in the Control Group.

\begin{tabular}{|c|c|c|c|c|c|}
\hline & \multicolumn{2}{|c|}{ Analysts } & \multicolumn{2}{|c|}{ Control Group } & \multirow[b]{2}{*}{ Range } \\
\hline & M & $95 \% \mathrm{CI}$ & $\mathrm{M}$ & $95 \% \mathrm{CI}$ & \\
\hline Intelligence Dilemmas & 2.90 & $2.53-3.28$ & 3.64 & $3.32-3.96$ & $1-7$ \\
\hline Utilitarianism & 0.35 & $0.27-0.43$ & 0.31 & $0.23-0.39$ & $0-1$ \\
\hline Deontology & 0.85 & $0.77-0.93$ & 0.85 & $0.78-0.93$ & $0-1$ \\
\hline SDO & 2.46 & $2.12-2.80$ & 2.05 & $1.73-2.36$ & $1-7$ \\
\hline Security & 5.47 & $5.12-5.81$ & 5.28 & $4.84-5.73$ & $1-7$ \\
\hline Tradition & 3.42 & $2.91-3.93$ & 3.50 & $2.91-4.10$ & $1-7$ \\
\hline Conformity & 4.56 & $4.12-5.00$ & 4.63 & $4.12-5.13$ & $1-7$ \\
\hline Political Conservatism & 3.54 & $3.20-3.89$ & 3.46 & $2.93-4.00$ & $1-12$ \\
\hline
\end{tabular}

Note. $\mathrm{SDO}=$ Social Dominance Orientation.

Next, we calculated point-biserial correlations between the responses to the ethics-ofintelligence dilemmas and each of the predictor variables (see Table 2). Responses to the ethics-of-intelligence dilemmas were significantly positively correlated with participants' group $(0=$ analyst, $1=$ control $)$ and social dominance, and significantly negatively correlated with the tendency to provide deontological resolutions to the classical moral dilemmas.

\section{Table 2}

Correlations Between Each of the Measured Variables.

\begin{tabular}{lccccccccc}
\hline & $\mathbf{1}$ & $\mathbf{2}$ & $\mathbf{3}$ & $\mathbf{4}$ & $\mathbf{5}$ & $\mathbf{6}$ & $\mathbf{7}$ & $\mathbf{8}$ & $\mathbf{9}$ \\
\hline 1. Group & -- & & & & & & & & \\
2. Intelligence & $\mathbf{3 3 *}$ & -- & & & & & & \\
Dilemmas & .05 & .14 & -- & & & & & \\
3. Utilitarianism & -.05 & & & & & & \\
4. Deontology & .02 & $\mathbf{- . 2 4 *}$ & $-.26 *$ & -- & & & & \\
5. SDO & -.19 &. $\mathbf{2 2} *$ & -.06 & -.11 & -- & & & \\
6. Security & -.10 & -.01 & .17 & -.19 & .18 & -- & & \\
7. Tradition & $<.01$ & -.01 & -.13 & $<.01$ & $\mathbf{. 3 7 * *}$ & $\mathbf{. 4 2} * *$ & -- & & \\
8. Conformity & $<.01$ & -.18 & -.12 & .18 & -.05 & $\mathbf{. 6 2} * *$ & $\mathbf{. 4 3} * *$ & -- & \\
9. Conservatism & -.03 & .07 & -.13 & .05 & $\mathbf{. 3 5 *}$ & $\mathbf{. 4 2} * *$ & $\mathbf{. 6 5} * *$ & $\mathbf{. 4 3} * *$ & -- \\
\hline
\end{tabular}

Note. Group $(0=$ professional, $1=$ control group $) ; \mathrm{SDO}=$ Social Dominance Orientation; ${ }^{*} p<.05, * * p \leq .001$. 
To assess the contribution of each predictor on the responses to the ethics-of-intelligence dilemmas, a multiple regression analysis was run. Variables inserted and results are presented in Table 3. Overall, the model accounted for $28.1 \%$ of the variance in participants' responses to the dilemmas, $F(8,75)=3.27, p=.003$. However, only participants' group and SDO scores were found to be significant predictors.

\section{Table 3}

Multiple Regression Predicting Responses to Ethics-of-Intelligence Dilemmas.

\begin{tabular}{lcccc}
\hline & $\mathrm{B}(95 \% \mathrm{CI})$ & $\beta$ & $\mathrm{T}$ & $p$ \\
\hline Group & $\mathbf{0 . 9 1}(\mathbf{0 . 4 3}-\mathbf{1 . 3 8})$ & $\mathbf{. 4 1}$ & $\mathbf{3 . 8 3}$ & $<. \mathbf{0 0 1}$ \\
Utilitarianism & $0.71(-0.31-1.73)$ & .16 & 1.39 & .171 \\
Deontology & $-0.65(-1.74-0.45)$ & -.14 & -1.18 & .242 \\
SDO & $\mathbf{0 . 2 9}(\mathbf{0 . 0 2}-\mathbf{0 . 5 6 )}$ & $\mathbf{. 2 6}$ & $\mathbf{2 . 1 5}$ & $\mathbf{. 0 3 5}$ \\
Security & $-0.03(-0.31-0.25)$ & -.03 & -0.20 & .841 \\
Tradition & $-0.11(-0.30-0.08)$ & -.17 & -1.18 & .244 \\
Conformity & $-0.09(-0.33-0.15)$ & -.12 & -0.78 & .437 \\
Conservatism & $0.15(-0.07-0.38)$ & .20 & 1.34 & .183 \\
\hline
\end{tabular}

Note. Group $(0=$ professional, $1=$ control group $) ; \mathrm{SDO}=$ Social Dominance Orientation.

\section{The Contribution of SDO Separately for Group}

Having found that group (professionals, control) significantly predicted participants' resolutions to the ethics-of-intelligence dilemmas, we next run two separated multiple regression analyses, one for each group. Results are presented in Table 4. Whereas responses to the dilemmas in the control group were not significantly predicted by any of the variables included in the model, $R^{2}=.14, F(7,33)=0.77, p=.619$, intelligence analysts' responses were predicted by SDO and Tradition scores. In this latter model, we inserted as predictors also the number of years spent working as an intelligence analyst and the sector (public, private). Overall, the model accounted for $44.3 \%$ of the variance in intelligence analysts' responses, $F(9,24)=2.12, p=.068$. 


\section{Table 4}

Multiple Regressions Predicting Responses to Ethics-of-Intelligence Dilemmas Separated by Participants' Group (Analysts, Control).

\begin{tabular}{|c|c|c|c|c|c|c|c|c|}
\hline & \multicolumn{4}{|c|}{ Analysts Group } & \multicolumn{4}{|c|}{ Control Group } \\
\hline & $\mathrm{B}(95 \% \mathrm{CI})$ & $\mathrm{B}$ & $\mathrm{T}$ & $\mathrm{p}$ & B $(95 \% \mathrm{CI})$ & $\beta$ & $\mathrm{T}$ & $\mathrm{p}$ \\
\hline Utilitarianism & $\begin{array}{c}0.58 \\
(-1.14-2.31)\end{array}$ & .13 & 0.70 & .493 & $\begin{array}{c}0.37 \\
(-1.11-1.85)\end{array}$ & .10 & 0.51 & .613 \\
\hline Deontology & $\begin{array}{c}-0.42 \\
(-2.11-1.27)\end{array}$ & -.09 & -0.52 & .611 & $\begin{array}{c}-0.98 \\
(-2.68-0.72)\end{array}$ & -.23 & -1.17 & .249 \\
\hline SDO & $\begin{array}{c}0.54 \\
(0.09-0.98)\end{array}$ & .49 & 2.50 & .020 & $\begin{array}{c}0.13 \\
(-0.26-0.51)\end{array}$ & .12 & 0.67 & .507 \\
\hline Security & $\begin{array}{c}0.06 \\
(-0.45-0.57)\end{array}$ & .06 & 0.25 & .805 & $\begin{array}{c}-0.04 \\
(-0.43-0.34)\end{array}$ & -.06 & -0.23 & .823 \\
\hline Tradition & $\begin{array}{c}-0.41 \\
\left(-0.75^{-}-0.06\right)\end{array}$ & -.52 & -2.42 & .023 & $\begin{array}{c}0.01 \\
(-0.28-0.29)\end{array}$ & .01 & 0.05 & .958 \\
\hline Conformity & $\begin{array}{c}-0.17 \\
(-0.57-0.23)\end{array}$ & -.20 & -0.87 & .393 & $\begin{array}{c}-0.10 \\
(-0.46-0.27)\end{array}$ & -.15 & -0.54 & .590 \\
\hline Conservatism & $\begin{array}{c}0.34 \\
(-0.14-0.82)\end{array}$ & .32 & 1.47 & .154 & $\begin{array}{c}0.10 \\
(-0.19-0.40)\end{array}$ & .17 & 0.70 & .486 \\
\hline Years Analyst & $\begin{array}{c}-0.01 \\
(-0.05-0.02)\end{array}$ & -.12 & -0.68 & .505 & -- & -- & -- & -- \\
\hline Sector & $\begin{array}{c}0.78 \\
(-0.03-1.58) \\
\end{array}$ & .35 & 2.00 & .057 & -- & -- & -- & -- \\
\hline
\end{tabular}

Note. Group ( 0 = professional, $1=$ control group $) ; \mathrm{SDO}=$ Social Dominance Orientation; Sector $(0=$ public, $1=$ private $)$.

As shown in Figure 1, for the analysts, higher SDO scores were associated with a greater tendency to provide a utilitarian resolution to the ethics-of-intelligence dilemmas. A linear regression with SDO as the only independent variable and responses to dilemmas as the outcome variable confirmed this result, $\mathrm{B}=0.44(0.11,0.77), \beta=.40, t(38)=2.67, p=.011$. Instead, the predictive relationship that was found between Tradition scores and responses to ethics-of-intelligence dilemmas may be explained by the fact that Tradition scores, although not significantly correlated with responses to dilemmas, $r=-.06$, were highly correlated with SDO, $r=.49, p=.002$. This line of reasoning is confirmed by the fact that if 
inserted as the only predictor variable in a linear regression analysis, Tradition scores do not significantly predict analysts' responses to the ethics-of-intelligence dilemmas, $\mathrm{B}=-0.04(-$ $0.29,0.21), \beta=-.06, t(37)=-0.33, p=.743$.

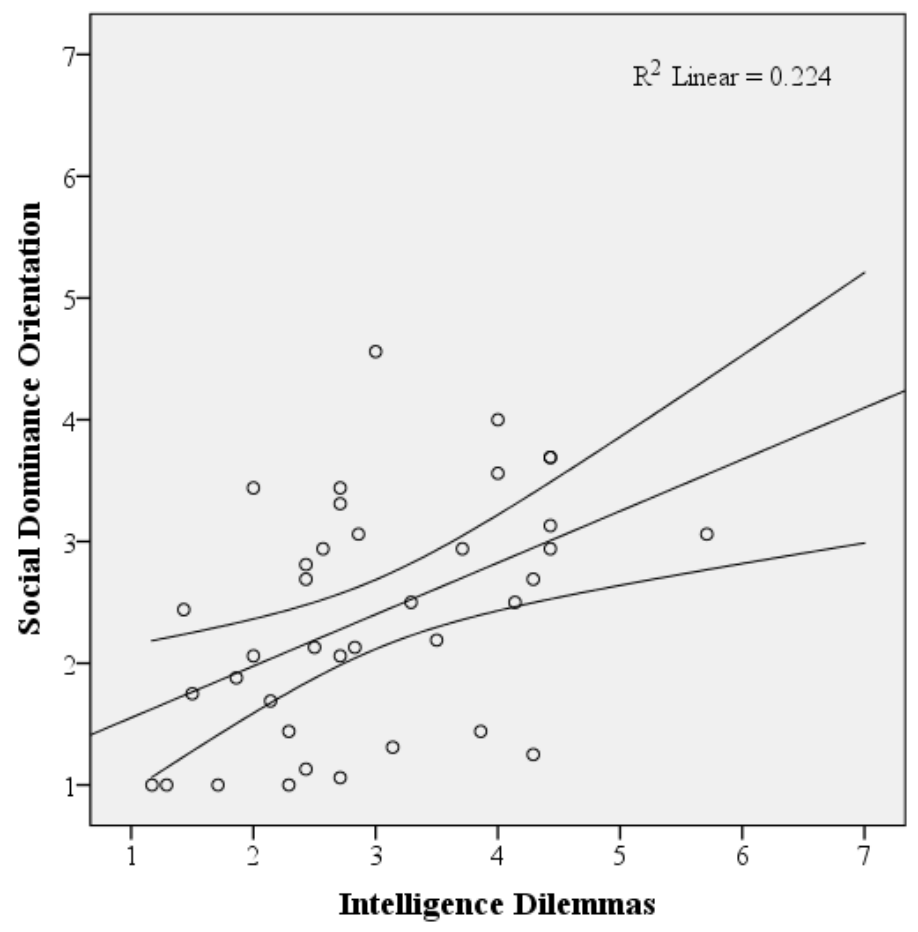

Figure 1. Intelligence analysts' responses to the ethics-of-intelligence dilemmas $(1=$ the action is not at all permitted, $7=$ the action is very much permitted) as a function of Social Dominance Orientation scores $(1=$ strong aversion to hierarchy and inequality among social groups, 7 = strong preference for hierarchy and inequality among social groups).

\section{Discussion}

The present study investigated how real intelligence analysts responded to ethics-ofintelligence dilemmas, i.e. situations where the story's protagonist, an intelligence analyst, has to decide about whether to violate deontology for the benefit of his/her work either as an intelligence agent or as an academic. On average, professionals judged violating a 
deontological rule (e.g., using leaked information to produce intelligence without a formal permission) close to 'somewhat' acceptable, but still significantly less somewhat acceptable compared to the control group of non-professionals. Moreover, we found that analysts' resolutions of ethics-of-intelligence dilemmas were predicted by SDO scores. Specifically, analysts high in SDO tended to judge the utilitarian resolution more acceptable. No other variables were found to be useful in explaining variability in participants' answers to the ethics-of-intelligence dilemmas.

Whereas SDO scores predicted resolutions of ethics-of-intelligence dilemmas in the professional group but not in the control group, the two groups did not differ in their average SDO level. It could be worth noting that both groups had an average score between 2 and 2.5 , which is very close to the average SDO score reported in the validation study of the scale, which is 2.6 (Ho et al., 2015; see also Fischer et al., 2012). Although SDO scores can range between 1 and 7 with a midpoint of 4 , in reality they tend to be skewed toward the lower end of the scale; therefore, because a score around 2.6 can be interpreted as representing neither strong opposition nor strong endorsement of intergroup hierarchy and anti-egalitarianism, we can conclude that both our samples were not characterized as either strongly in favor or opposed to intergroup hierarchy and anti-egalitarianism.

Still, SDO scores did help explain a significant amount of variability in analysts' responses to the ethics-of-intelligence dilemmas. Being more social dominance oriented was associated with having the tendency to think that sometimes violating deontology can be deemed acceptable and should be done. In other words, the more the person endorses intergroup hierarchy and anti-egalitarianism, the more he/she also thinks that, for instance, a former intelligence officer, now a scholar, should use classified evidence in her possession 
to fulfill her research duties, or that an intelligence analyst should use at his job leaked information accessed at his home which he was unable to retrieve from the Intelligence Community, or, again, illegally spy even the private sexual life of a veteran soldier who is a suspected informer of Al-Qaeda.

SDO reflects how much a person endorses intergroup hierarchy, i.e. the desire for existing dominant groups to have more status and power than subordinate groups, but does not necessarily reflect ingroup favoritism, i.e. the desire that one's own group dominates others. However, there is evidence that SDO can be positively associated with ingroup favoritism among individuals that belong to dominant groups (Sidanius et al., 2016; Sidanius \& Pratto, 1999; Thomsen et al., 2010). And, though with some caveats, we can reasonably argue that intelligence analysts belong to a dominant group or hold high positions within the social hierarchy. Moreover, please recall that SDO can be associated with concerns for the security of the dominant group (e.g., one's country) especially when security is threatened by outgroups.

If taken together with these observations, the predictive relationship between SDO and responses to ethics-of-intelligence dilemmas reported in the current study suggests that, within the intelligence analyst group, those who were more prone to desire their country or ingroup to prevail over others were also those who more readily were lenient toward possible violations of deontology when these violations can result in a greater good for their state/company or the success of a mission. SDO may thus be linked to prioritizing a utilitarian resolution of the dilemmas rather than a deontological one.

In the current study, the first of this kind that we are aware of in the open literature, we explored some aspects of the ethics of real intelligence analysts. Needless to say, that was 
just a drop in the bucket, and many more interesting aspects of the ethics of intelligence remain to be uncovered. For instance, a valuable avenue for future research would be to investigate how being an analyst can modify one's intuitions about key notions of authority, social power, justice, war, knowledge, and in general morality in the context of the intelligence process. This research may usefully inform the current debate within intelligence community about the definition of the moral boundaries related to intelligence process (e.g., Goldman, 2013, 2018; Erskine, 2004; Herman, 2004; Petrauskaite \& Šaltenis, 2018; Quinlan, 2007; see also Pili, 2018). Another fruitful direction could be to investigate whether there are significant differences among intelligence agencies, where the question is whether the culture of the specific institution shapes intelligence analysts' morality and perception. ${ }^{4}$ Lastly, the perhaps most fascinating and important study would aim to investigate the conditions of 'moral acceptability' of treason.

In conclusion, we assessed how intelligence analysts see their own professional ethics and found that social dominance orientation can predict the tendency to endorse a utilitarian resolution to the ethics-of-intelligence dilemmas. Our study is the first known one that employed a quantitative methodological approach in order to elucidate some key factors of the real ethics of intelligence.

\footnotetext{
${ }^{4}$ This point was suggested to one of the authors by Joseph Hatfield (US Naval War College \& Intelligence Professional).
} 


\section{References}

Bostyn, D. H., Roets, A., \& Van Hiel, A. (2016). Right-wing attitudes and moral cognition: Are right-wing authoritarianism and social dominance orientation related to utilitarian judgment? Personality and Individual Differences, 96, 164-171. http://dx.doi.org/10.1016/j.paid.2016.03.006

Conway, P., \& Gawronski, B. (2013). Deontological and utilitarian inclinations in moral decision making: A process dissociation approach. Journal of Personality and Social Psychology, 104, 216-235. http://dx.doi.org/10.1037/a0031021

Dunwoody, P. T., \& McFarland, S. G. (2018). Support for anti-Muslim policies: The role of political traits and threat perception. Political Psychology, 39, 89-106. https://doi.org/10.1111/pops.12405

Erskine, T. (2004). 'As rays of light to the human soul'? Moral agents and intelligence gathering. Intelligence and National Security, 19, 359-381. https://doi.org/10.1080/0268452042000302047

Feldman, S., \& Stenner, K. (1997). Perceived threat and authoritarianism. Political Psychology, 18, 741-770. https://doi.org/10.1111/0162-895x.00077

Fischer, R., Hanke, K., \& Sibley, C. G. (2012). Cultural and institutional determinants of social dominance orientation: A cross-cultural meta-analysis of 27 societies. Political Psychology, 33, 437-467. https://doi.org/10.1111/j.1467-9221.2012.00884.x

Gill, P., \& Phythian, M. (2012). Intelligence studies: some thoughts on the state of the art. Annals of the University of Bucharest, 14, 5-17.

Gill, P., \& Phythian, M. (2016). What is intelligence studies? The International Journal of Intelligence, Security, and Public Affairs, 18, 5-19. 


\section{https://doi.org/10.1080/23800992.2016.1150679}

Goldman, J. (2006). Words of Intelligence: A dictionary. Lanham, Maryland: Scarecrow Press.

Goldman, J. (2013). Teaching about intelligence and ethics. Journal of U.S. Intelligence Studies, 20, 79-83.

Goldman, J. (2018). The ethics of research in Intelligence Studies: scholarship and emerging discipline. International Journal of Intelligence and Counterintelligence, 31, 342-356. https://doi.org/10.1080/08850607.2018.1417638

Greene, J. D., Sommerville, R. B., Nystrom, L. E., Darley, J. M., \& Cohen, J. D. (2001). An fMRI investigation of emotional engagement in moral judgment. Science, 293, 21052108. http://dx.doi.org/10.1126/science.1062872

Herman, M. (2004). Ethics and intelligence after September 2001. Intelligence and National Security, 19, 342-358. https://doi.org/10.1080/0268452042000302038

Ho, A. K., Sidanius, J., Kteily, N. S., Sheehy-Skeffington, J., Pratto, F., Henkel, K. E., ... Stewart, A. L. (2015). The nature of social dominance orientation: Theorizing and measuring preferences for intergroup inequality using the new $\mathrm{SDO}_{7}$ scale. Journal of Personality and Social Psychology, 109, 1003-1028.

https://doi.org/10.1037/pspi0000033

Horn, E. (2003). Knowing the enemy: The epistemology of secret intelligence. Grey Room,

\section{1, 58-85. https://doi.org/10.1162/15263810360661435}

Kleppestø, T. H., Eftedal, N. H., \& Thomsen, L. (2020). Social Dominance Orientation (SDO). In Encyclopedia of Evolutionary Psychological Science. Springer International Publishing. https://doi.org/10.1007/978-3-319-16999-6_2602-1 
Patil, I., Zucchelli, M. M., Kool, W., Campbell, S., Fornasier, F., Calò, M., ... \& Cushman, F. (2020). Reasoning supports utilitarian resolutions to moral dilemmas across diverse measures. Journal of Personality and Social Psychology, 1-18.

\section{https://doi.org/10.1037/pspp0000281}

Petrauskaitè, A., \& Šaltenis, L. (2018). The interaction between intelligence operations and ethics in the context of national security: a theoretical review of the problem. Lithuanian Annual Strategic Review, 16, 401-424. https://doi.org/10.2478/lasr-2018-0014

Pili, G. (2018). Epistemology and intelligence - some philosophical problems to be solved. The International Journal of Intelligence, Security, and Public Affairs, 20, 252-270. https://doi.org/10.1080/23800992.2018.1532180

Pili, G. (2019). Toward a philosophical definition of intelligence. The International Journal of Intelligence, Security, and Public Affairs, 21, 162-190.

\section{https://doi.org/10.1080/23800992.2019.1649113}

Pratto, F., Sidanius, J., \& Levin, S. (2006). Social dominance theory and the dynamics of intergroup relations: Taking stock and looking forward. European Review of Social Psychology, 17, 271-320. https://doi.org/10.1080/10463280601055772

Pratto, F., Sidanius, J., Stallworth, L., \& Malle, B. F. (1994). Social dominance orientation: A personality variable predicting social and political attitudes. Journal of Personality and Social Psychology, 67, 741-763. https://doi.org/10.1037/0022-3514.67.4.741

Quinlan, M. (2007). Just intelligence: Prolegomena to an ethical theory. Intelligence and National Security, 22, 1-13. https://doi.org/10.1080/02684520701200715 
Schwartz, S. H., Cieciuch, J., Vecchione, M., Davidov, E., Fischer, R., Beierlein, C., ... \& Dirilen-Gumus, O. (2012). Refining the theory of basic individual values. Journal of Personality and Social Psychology, 103, 663-688. https://doi.org/10.1037/a0029393

Sheehy-Skeffington, J., \& Thomsen, L. (2020). Egalitarianism: psychological and socioecological foundations. Current Opinion in Psychology, 32, 146-152. https://doi.org/10.1016/j.copsyc.2019.08.014

Sidanius, J., Cotterill, S., Sheehy-Skeffington, J., Kteily, N., \& Carvacho, H. (2016). Social dominance theory: Explorations in the psychology of oppression. In C. G. Sibley \& F. K. Barlow (Eds.), The Cambridge handbook of the psychology of prejudice (pp. 149187). Cambridge, UK: Cambridge University Press.

Sidanius, J., \& Pratto, F. (1999). Social dominance: An intergroup theory of social hierarchy and oppression. Cambridge, UK: Cambridge University Press.

Thomsen, L., Green, E. G., Ho, A. K., Levin, S., van Laar, C., Sinclair, S., \& Sidanius, J. (2010). Wolves in sheep's clothing: SDO asymmetrically predicts perceived ethnic victimization among White and Latino students across three years. Personality and Social Psychology Bulletin, 36, 225-238. https://doi.org/10.1177/0146167209348617

Thomsen, L., Green, E. G., \& Sidanius, J. (2008). We will hunt them down: How social dominance orientation and right-wing authoritarianism fuel ethnic persecution of immigrants in fundamentally different ways. Journal of Experimental Social Psychology, 44, 1455-1464. https://doi.org/10.1016/j.jesp.2008.06.011

Warner, M. (2002). Wanted: a definition of "intelligence". Studies in Intelligence, 46, 1522. 


\section{Supplementary Materials}

1. Ethics-of-Intelligence Dilemmas

2. Classical Moral Dilemmas

3. Social Dominance Orientation Scale

4. Value Survey (Security-societal, Tradition, Conformity-rules)

5. Qualitative Assessment of Participants' Justifications 


\section{Ethics-of-Intelligence Dilemmas}

\section{Dilemma \#1}

Frank Zane, a signals intelligence analyst for an U.S. Agency XXX, has been at his current position for the past ten years. Having enrolled in evening classes at the local university, his national security course this semester is "European Radical Terrorism."

Tonight, the professor is focusing on a particular terrorist organization. The group, WazimbiBegol, is unknown to the public, and the U.S. government refuses to mention it for several reasons that intersect national security and politics. Nevertheless, earlier this week, Wikileaks published the 28-page highly classified National Intelligence Estimate (NIE) detailing its organizational chart, missions, and objectives. Yet, the group remains classified and officially 'non-existent' by the U.S. government.

At his job Frank has been tracking this group for the last three years through their communication networks. Tonight's assignment was to read the leaked NIE (to which he contributed writing as part of an Intelligence Community project) and discuss it in class.

Frank now has an ethical dilemma. Although widely available on the Internet, the NIE remains classified by the federal government. As with most leaked classified documents found on the Internet, the government has neither confirmed nor denied the validity of this report. Some students in the class know that Frank works in the Intelligence Community.

How much do you think that Frank should participate in the discussion of a leaked document?

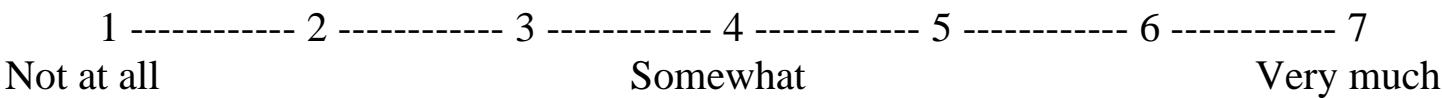

Please provide a brief explanation for the answer you chose to give.

\section{Dilemma \#2}

Alexandra George is a former intelligence officer deployed in Vietnam during the war (19661970). She left the agency and now she is working as a post-doctoral fellow in a good academic institution.

The director of the Master of History and Intelligence asked her to organize the next course programme on the history of intelligence in Vietnam. She agrees as far as she is an academic expert in the field. However, during her work for publishing a paper which is also to be presented during the course, she realizes that the open sources do not fully consider some actual facts that she knows because of her work as an intelligence officer and that would eventually explain the historical events she should cover in both the paper and the lessons.

Alexandra now has an ethical dilemma. From one side, she knows that if she does not consider the evidence in her possession still classified, she cannot really make a truthful and meaningful explanation of what happened during the war. From another side, if she reveals the secret evidence, she would fulfill her research duties.

How much do you think that Alexandra should use the evidence in her possession? (1-7)

Please provide a brief explanation for the answer you chose to give. 


\section{Dilemma 3\#}

In a similar case but coming to intelligence methods (such as how to write a report, how to aggregate data consistently, how to check sources etc.) rather than historical facts about the war how much do you think that Alexandra should use her prior knowledge in the class? (17)

Please provide a brief explanation for the answers you chose to give.

\section{Dilemma \#4}

Recently hired counterintelligence analyst Charles Johnson, having accessed Wikileaks at home, was reviewing some of the one million documents that had recently become available. A foreign intelligence XXX's report outlines overseas criminal activity by an organized gang that is under investigation by his Cleveland field office. The leaked XXX report provides information that Charles was unable to receive from the Intelligence Community even after numerous requests.

A further complication is that Johnson is a new Bureau employee and it could take from 24 to 200 days before he can obtain his full security clearances.

Charles now has an ethical dilemma. He can either take notes and use this information the next day at his job or disregard any and all the information and continue to resubmit and fill out request for information forms to the $\mathrm{XXX}$ on the information he is now accessing from his home.

How much do you think that Charles should take notes and use this information the next day at his job? (1-7)

Please provide a brief explanation for the answer you chose to give.

\section{Dilemma \#5}

In a family, the mother is an intelligence analyst, and the daughter is not. The daughter's boyfriend's family is active in drug and financial crimes. However, it is not involved in any kind of terrorist activities. The daughter knows about the family's background and activities, but she and the boy are still in a relationship. Moreover, the boy is actually innocent. Even though he knows about his family's activities, he is not involved at all in them.

The mother's chief instructed her to investigate on the family. The mother started working on the files available to her within her agency but soon realized that this will not be enough, and that many more information can be informally retrieved from or with the help of her daughter. In addition, the mother knows that the needed information can be obtained only through a direct informer.

The mother has thus an ethical dilemma. Should the mother ask for the information to the daughter, without informing her about the investigation? (1-7)

Please provide a brief explanation for the answer you chose to give. 


\section{Dilemma \#6}

Should the mother ask to the daughter to spy knowing that the boy is actually innocent? (17)

Please provide a brief explanation for the answer you chose to give.

\section{Dilemma \#7}

Emma is a CIA (Central Intelligence Agency) agent. The agency believes that there will be another major terrorist attack (9/11 magnitude). She has the duty to check whether a veteran soldier was turned as an informer of an Al-Qaeda cell.

After asking for the permission, she bugged the soldier's house from the living room to the bathroom having the chance to watch all his ordinary life. She is able to watch his (quite problematic) sexual life about which she scrupulously takes notes and observations to find clues and evidence about his becoming an informer.

Knowing that Emma does not have the legal permission, how much is she ethically allowed to spy and violate his privacy?

Should she pursue all the surveillance observing even his private sexual life? (1-7)

Please provide a brief explanation for the answer you chose to give. 


\section{Classical Moral Dilemmas}

Scenarios were selected among the ones developed by Conway \& Gawronski (2013). Conway, P., \& Gawronski, B. (2013). Deontological and utilitarian inclinations in moral decision making: A process dissociation approach. Journal of Personality and Social Psychology, 104, 216-235. http://dx.doi.org/10.1037/a0031021

\section{Car Accident}

\section{Incongruent Version}

You are driving through a busy city street when all of a sudden a young mother carrying a child trips and falls into the path of your vehicle. You are going too fast to break in time; your only hope is to swerve out of the way. Unfortunately, the only place you can swerve is currently occupied by a little old lady. If you swerve to avoid the young mother and baby, you will seriously injure or kill the old lady.

Is it appropriate to swerve and hit the old lady in order to avoid the young mother and child?

\section{Congruent Version}

You are driving through a busy city street when all of a sudden a young mother carrying a child trips and falls into the path of your vehicle. You are going too fast to break in time; your only hope is to swerve out of the way. Unfortunately, the only place you can swerve is currently occupied by a group of children on their way to elementary school. If you swerve to avoid the young mother and baby, you will seriously injure or kill several of them.

Is it appropriate to swerve and hit the schoolchildren in order to avoid the young mother and child?

\section{Crying Baby}

\section{Incongruent Version}

It is war time. Enemy soldiers have taken over your village. They have orders to kill all remaining civilians. You and some of your townspeople have sought refuge in the cellar of a large house. Outside you hear the voices of soldiers who have come to search the house for valuables. A baby with no parents begins to cry loudly. You cover her mouth to block the sound. If you remove your hand from the baby's mouth her crying will summon the attention of the soldiers who will kill you and the others hiding out in the cellar. To save yourself and the others you must smother the child to death.

Is it appropriate for you to smother the child in order to save yourself and the other townspeople from being killed?

\section{Congruent Version}

It is war time. Enemy soldiers have taken over your village. They have orders to capture all remaining civilians to make them work quarrying stone in a mine. You and some of your townspeople have sought refuge in the cellar of a large house. Outside you hear the voices of soldiers who have come to search the house for valuables. A baby with no parents begins to cry loudly. You cover her mouth to block the sound. If you remove your hand from her mouth the crying will summon the attention of the soldiers who will capture you and the others hiding out in the cellar. To save yourself and the others from laboring in the mine you must smother the child to death.

Is it appropriate for you to smother the child in order to save yourself and the other townspeople from being captured? 


\section{Relationship \\ Incongruent Version}

You are divorced now and your former spouse lives far away. You don't expect to see your former spouse for a very long time. However, you have recently started dating a new person that is positively wonderful. Your new partner is head over heels in love for the first time and you feel equally strong about your partner. You want to do everything in your power to keep the relationship progressing smoothly to what you believe will be a second marriage. Unfortunately, your new partner has told you many times that dating someone who is divorced is totally unacceptable. It is expressly forbidden in your partner's religion. Your partner doesn't know about your ex-spouse. You consider simply pretending that you have never been divorced so that your current relationship can continue.

Is it appropriate for you to leave your new partner in the dark about your previous relationship in order to keep her/him happy and the relationship alive?

\section{Congruent Version}

You are divorced now and your former spouse lives far away. You don't expect to see your former spouse for a very long time. However, you have recently started dating a new person that is positively wonderful. Your new partner is head over heels in love for the first time and you feel equally strong about your partner. You want to do everything in your power to keep the relationship progressing smoothly to what you believe will be a second marriage. Unfortunately, your ex-spouse gave you a very serious and incurable Sexually Transmitted Disease (STD). Your partner does not know about it. You consider simply pretending that you don't know about the STD so that your current relationship can continue.

Is it appropriate for you to leave your new partner in the dark about your STD in order to keep her/him happy and the relationship alive?

\section{Torture}

\section{Incongruent Version}

You are a police officer, and have recently caught a criminal you have been hunting for some time. He is allegedly responsible for rigging a series of explosive devices: some that have already gone off and some that have yet to detonate. He places explosives outside city cafes and sets them to go off at a time when people are drinking coffee on the patios. In this manner, he has injured many people and might injure many more. Now that the criminal is in custody, you want to know where the unexploded bombs are so you can defuse them. He refuses to talk, so you decide to use "aggressive interrogation techniques" like holding his head under water and beating him.

Is it appropriate for you to use "aggressive interrogation techniques" in order to find and defuse the unexploded bombs?

\section{Congruent Version}

You are a police officer, and have recently caught a criminal you have been hunting for some time. He is allegedly responsible for rigging a series of explosive devices: some that have already gone off and some that have yet to detonate. He places explosives outside city cafes and sets them to go off at a time when no one is around. His explosives are inside paint cans so that they spray nearby objects with paint. In this manner, he has sprayed many cafes with paint and might spray many more. Now that the criminal is in custody, you want to know where the unexploded bombs are so you can defuse them. He refuses to talk, so you decide 
to use "aggressive interrogation techniques" like holding his head under water and beating him.

Is it appropriate for you to use "aggressive interrogation techniques" in order to find and defuse the unexploded bombs?

\section{Border Crossing}

Incongruent Version

You are a soldier guarding a border checkpoint between your nation and one troubled by insurgent violence. You notice a young man in a cheap car approaching the checkpoint with a determined look on his face. You suspect he means to bomb the checkpoint, killing all the soldiers inside. He is rapidly approaching your station.

Is it appropriate for you to shoot and kill the approaching man?

\section{Congruent Version}

You are a soldier guarding a border checkpoint between your nation and one troubled by insurgent violence. You notice a young man in a cheap car approaching the checkpoint with a determined look on his face. You suspect he means to cross the border in order to work illegally inside your country. He is rapidly approaching your station.

Is it appropriate for you to shoot and kill the approaching man? 


\section{Social Dominance Orientation Scale}

Instructions: Below are a series of statements with which you may either agree or disagree. For each statement, please indicate the degree of your agreement/disagreement by circling the appropriate number from 1 (strongly disagree/disapprove) to 7 (strongly agree/favor). Once again, remember that your first responses are usually the most accurate.

Items were:

1. Some groups of people are just more worthy than others

2. In getting what your group wants, it is sometimes necessary to use force against other groups

3. Superior groups should dominate inferior groups

4. To get ahead in life, it is sometimes necessary to step on other groups

5. If certain groups of people stayed in their place, we would have fewer problems

6. It's probably a good thing that certain groups are at the top and other groups are at the bottom

7. Inferior groups should stay in their place

8. Sometimes other groups must be kept in their place

9. It would be good if all groups could be equal

10. Group equality should be our ideal

11. All groups should be given an equal chance in life

12. We should do what we can to equalize conditions for different groups

13. Increased social equality

14. We would have fewer problems if we treated different groups more equally

15. We should strive to make incomes more equal

16. No one group should dominate in society

See: Pratto, F., Sidanius, J., Stallworth, L., \& Malle, B. F. (1994). Social dominance orientation: A personality variable predicting social and political attitudes. Journal of Personality and Social Psychology, 67, 741-763. https://doi.org/10.1037/0022$\underline{3514.67 .4 .741}$ 


\section{Value Survey (Security-societal, Tradition, Conformity-rules)}

Instructions: Here we briefly describe some people. Please read each description and think about how much each person is or is not like you. Circle the number that shows how much the person in the description is like you.

How much like you is this person?

$$
1 \text {------- } 2 \text {------- } 3 \text {------- } 4 \text {------- } 5 \text {------- } 6 \text {------- } 7
$$

Completely NOT like me Completely like me

Items were:

Security-societal

It is important to him that his country protect itself against all threats.

He wants the state to be strong so it can defend its citizens.

Having order and stability in society is important to him.

\section{Tradition}

It is important to him to maintain traditional values or beliefs.

Following his family's customs or the customs of a religion is important to him. He strongly values the traditional practices of his culture.

\section{Conformity-rules}

He believes he should always do what people in authority say.

It is important to him to follow rules even when no one is watching. Obeying all the laws is important to him.

See: Schwartz, S. H., Cieciuch, J., Vecchione, M., Davidov, E., Fischer, R., Beierlein, C., ... $\&$ Dirilen-Gumus, O. (2012). Refining the theory of basic individual values. Journal of Personality and Social Psychology, 103, 663-688. https://doi.org/10.1037/a0029393 


\section{Qualitative Assessment of Participants' Justifications}

Dilemma \#1 - Frank Zane (participating or not participating in the lesson?)

\section{Code Main Issue}

$1 \quad$ Frank must read the leaked document and participate in the lesson

$2 \quad$ Frank can be part of the lesson but only passively

3 Frank must not read nor participate

$4 \quad$ No reply

$\begin{array}{cc}\text { Analysts } & \text { Control } \\ 6 & 8 \\ 12 & 9 \\ 22 & 14 \\ 1 & 1\end{array}$

\section{Considerations \& Method}

Analysts are divided between those who believe that Frank can participate in the lesson but as a passive student (mainly listening and taking notes) and those who believe that Frank must not take any part in it. Legal issues related to the case were their primary concern. This was explicitly recognized by one participant, "I understand this question isn't asking about legality, but the ethics of the situation." However, analysts' great majority focused the attention to legal aspects only. Indeed, participants who agree in the leaked document usage are those who consider it to be open source information and then legally acceptable to use (still a minority).

The control group is divided on this dilemma. Though the majority of participants stated that Frank should not take part in the lesson even passively, the number of those who believe that Frank can actively participate was higher than in the analysts' group. In addition, answers were more homogeneous and less detailed than those of the analysts. 


\section{Dilemma \#2 - Alexandra (Vietnam post-doc)}

\begin{tabular}{|c|c|c|c|}
\hline Code & Main Issue & Analysts & Control \\
\hline 1 & Alexandra cannot release the information due to law & 30 & 21 \\
\hline 2 & $\begin{array}{l}\text { She can release the information trying to go around } \\
\text { the point, asking permission/playing to the edges }\end{array}$ & 6 & 5 \\
\hline 3 & She must release the information & 3 & 11 \\
\hline 4 & No reply & 2 & 4 \\
\hline
\end{tabular}

\section{Considerations \& Method}

The first category is composed of those who refused the possibility due to legal reasons. It was very consistent, as participants' answers that fell into this category had almost the same wording. Instead, responses in the second category were more nuanced where analysts assumed that the information can somehow be released. The last category includes those who would release even a classified information. First, there is an interesting presumption among the analysts. Namely, there is definitely open information, and there is still classified information, but a dilemma arises only when the information is classified. The analysts' great majority insists on not releasing the classified information because of the law. Only one analyst considered the oath problem (and then it can almost be stated that he/she posed an ethical problem). Some analysts explicitly stated that this is not an ethical dilemma but a legal issue, solved by the law itself (Alexandra cannot and should not release the still-classified information). Few analysts instead were moderately open to "playing the edges", namely, to put the classified information in their lesson background. Only three analysts stated explicitly that the information can be used.

The control group counts more participants considering Alexandra's duty to release the classified information, where participants stated that she has a duty toward the truth! However, the number of people who consider this mainly a legal dilemma is still the most numerous. They all consider legal reasons as the main argument. 


\section{Dilemma \#3 - Alexandra (disclosure of methods)}

\begin{tabular}{|c|c|c|c|}
\hline Code & Main Issue & Analysts & Control \\
\hline 1 & Alexandra cannot release the information due to law & 8 & 6 \\
\hline 2 & $\begin{array}{l}\text { She can release the information trying to go around } \\
\text { the point, asking permission/playing to the edges }\end{array}$ & 11 & 3 \\
\hline 3 & She must release the information & 20 & 24 \\
\hline 4 & No reply & 2 & 8 \\
\hline
\end{tabular}

\section{Considerations \& Method}

Because dilemma 3 is mainly an elaboration of dilemma 2, the aggregated categories are the same. Indeed, the analysts position themselves perfectly inside them, but in different distribution compared to dilemma 2. The clearer answers show the opinion of the majority: "Sources and methods related to collection are classified." but "Analytic methodology is not. Analytical tradecraft such as these aren't classified, so no ethical problem really exists." Basically, analysts consider in a reversed way releasing analytic methods from disclosing actual information or collection methods. Analytic methods are with "very unusual exception" already in the open media. Interestingly, this is what the analysts in the second category stated: there are no secret analytic methods but, if there are any, they must not be revealed. But, they argued, it won't be difficult to find something similar in the open media. And then using them is fine. So, in this case, category 2 and 3 are very close to one another. Only a minority of participants considers the problem equivalent to the one of dilemma 2, where sources and secret information were at stake. There, judgments were extremely uniform and clear on the side of denying access to that piece of information even for academic purposes.

In dilemma 2, the control sample was aligned with the analysts' group, though less polarized. Interesting exceptions explicitly stated that the analysts should have released the information exactly for ethical reasons. In dilemma 3, even more participants in the control group stated that methods can be released. Some of them stated that actually no o few analytic methods are indeed classified. Those who considered the problem looking to the possibility of classified methods are those who stated Alexandra must not use those in class. However, the majority of participants believe that Alexandra should definitely use the methods because they are not classified or it is easy to find something very similar to them in the open media. Eight replies were blank or under informative. 


\section{Dilemma \#4 - WikiLeaks}

$\begin{array}{llcc}\text { Code } & \text { Main Issue } & \text { Analysts } & \text { Control } \\ 1 & \text { He must use WikiLeaks information } & 10 & 16 \\ 2 & \text { Ask permission or declare the issue to the superior } & 14 & 7 \\ 3 & \text { He must not use WikiLeaks information } & 15 & 14 \\ 4 & \text { No reply } & 2 & 2\end{array}$

\section{Considerations \& Method}

Comparing the answers with those given to the previous dilemma, it can be noted that the average length increased. It seems that the analysts took the problem in a less clear-cut way. However, their arguments were very similar to one another. Ethically, the conundrum is played by three components: career, law prescription, and efficacy of the analysis. In addition, it seems that the analysts did not agree about what to do. The problem can be exemplified by this answer: "He should ask for guidance from his immediate superior as he is new and not fully cleared." Instead, participants who suggest using the information frame it as "open source", which is denied by the majority. Participants who denied the use of the information are split between those who are afraid of breaking the law because of career requirements, and those who are simply against this wrong practice. However, it is important to underline how differently this dilemma was perceived comparing to the previous one, looking at the length and typology of answers given.

The control group replied differently from the analysts' group. Though the number of "hard deniers" of Wikileaks use is similar, the number of people who suggested that Charles must use the information is increased. The intermediate category "Ask permission or declare the issue to the superior" is the one decreased in comparison with the analysts' group. In addition, there are some participants who agreed on using the Wikileaks information for ethical reasons (which was the main point): "He shouldn't, but if it keeps the criminal gang from destroying lives... then he should." There are participants who recognize the moral problem, but they disregard it because of law or career, "having the information is one thing, but using it is another. He could lose his job." Lastly, replies' length was shorter than the analysts' one, perhaps indicating that participants in the control group did not perceive a subtle point here. 


\section{Dilemma \#5 - When your daughter can be an informer...}

$\begin{array}{llcc}\text { Code } & \text { Main Issue } & \text { Analysts } & \text { Control } \\ 1 & \text { The mother must ask the daughter for information } & 9 & 15 \\ 2 & \begin{array}{l}\text { Stuck in between, conflict of interests to be solved by } \\ \text { another person }\end{array} & 18 & 4 \\ 3 & \text { The mother must not ask the daughter for information } & 10 & 17 \\ 4 & \text { No reply } & 2 & 5 \\ 5 & \text { Not clear } & 2 & -\end{array}$

\section{Considerations \& Method}

Dilemma 5 stroke all the analysts. They gave even longer and detailed and quite different explanations of their answer. Category 1 is the less numerous but still relevant. The extreme reply captures the main idea: "She is responsible toward the state, her daughter chose an enemy of the state, the family of the boys is enemy of the community not only of the state." Another kind of answer was "The daughter could be discovered and end up in worse trouble", pointing to the potential harm of the situation for the daughter. Category 2 was the most considered. Analysts pointed out a conflict of interest in the mother. She should not even consider the case, asking for a solution from her officer/manager ("First, it was unethical for the chief to ask the mother to investigate the boyfriend's family - she is too close to the family, via her daughter, and will be unable to evaluate any evidence in the investigation critically. Second, the mother would be involving an innocent third party, the daughter, who may not know anything. It is unethical to involve family members in intelligence operations when they are not employed, protected, or trained by the agency."). Lastly, though not strikingly numerous and relatively numerically closed to the first category, category 3 identified participants who denies the investigation without appealing to the conflict of interests ("Violate her daughter in order to score points at work? What foundation for ethics do you have?"). All in all, this dilemma was considered an ethical one, as one analyst considered it: "Real dilemma as involves the exploitation of personal relationship as a source: good spy=worse mother here." However, again, the main answer is legal, though here the ethical dilemma is considered as such explicitly. This is also proved by the diversity of the explanations reported. Though they can be aggregated, they still show quite an impressive difference of views on the problem, suggesting that participants believed that there was no clear solution.

Control group is more polarized, and participants' division is more on merely ethical ground (family ties vs. duty toward society) than on legal considerations. In addition, the explanations are more polarized and mainly aggregated on a yes/no position. So, participants who supported the investigation justified it by appealing to the positivity of the outcomes from a moral standpoint. Instead, participants who denied the option justified the unethical exploitation of the daughter. So, the moral tie toward the daughter was the main issue vis a vis the job's moral good. Only five participants pointed out the conflict of interest. 


\section{Dilemma \#6 - When your daughter can be an informer ... (part 2)}

\section{Code Main Issue}

1 The mother must inform the daughter

2 Stuck in between, conflict of interests to be solved by another person

3 The mother has not to inform the daughter

$4 \quad$ No reply

$5 \quad$ Not clear

$\begin{array}{cc}\text { Analysts } & \text { Control } \\ 2 & 11 \\ 14 & 3 \\ 21 & 22 \\ 2 & 4 \\ 2 & 1\end{array}$

\section{Considerations \& Method}

The categories are the same as the previous case because they are drawn by the same dilemma with a different, second question. This second question sees the analysts agreeing more than on any other dilemma. The distinction here is drawn basically between participants who argued for a conflict of interests (which should be settled by the handler of another person) and participants who argued for a clear refusal. The analysts were pretty united to not let the daughter know the situation, calling her own security as a reason. In this respect, in contrast with dilemma 5, the number of analysts that would use the daughter as a source is minimal (only two), and there is widespread agreement that the mother has to protect her daughter.

Even though the distribution of the control group's answers is similar to the one in dilemma 5, there is still a relevant number of interviewees that agreed on letting the daughter know about the case. As in the previous dilemma, the polarization toward extremes was clear. However, the control group was generally aligned with the analysts considering letting the daughter know very dangerous because of the potential harm this can cause to her. 


\section{Dilemma \#7 - When the case got hot}

$\begin{array}{llcc}\text { Code } & \text { Main Issue } & \text { Analysts } & \text { Control } \\ 1 & \text { Emma must proceed } & 17 & 21 \\ 2 & \text { Only if the person is not US citizen } & 6 & - \\ 3 & \text { Emma must } \text { not } \text { proceed } & 10 & 17 \\ 4 & \text { No reply } & 3 & 2 \\ 5 & \text { The question is not clear } & 5 & 1\end{array}$

\section{Considerations \& Method}

Analysts who recognized the legal action also agreed on using the information eventually disclosed during the sexual activity. However, analysts were mainly driven by legal observations, namely whether the operation is authorized or not. Thus, if the operation is authorized, Emma must proceed; if it is not, she must not. In the same fashion, some analysts consider privacy not so relevant in this context. Only a few analysts replied, considering mainly the ethical aspect of the dilemma: "From the ethical point of view, it is morally wrong to spy on the sexual lives of others, although the matter of national security can sometimes override this ethical model. Any information is valuable, as long as it is directly related to the case." Analysts mainly solve this dilemma by looking to the law and not to the value in danger. They encapsulated the legal framework's value, suggesting that is morally right what the law says is legally appropriate. If it is legally approved, then the action is also morally acceptable.

The control group showed an extreme polarization. They were almost entirely split into two categories. The first one advocated for breaching privacy because of terrorism threat: "if it is about terrorism, privacy can be breached". Instead, the second group believed that privacy must be preserved even in the face of a 9/11 scenario: "Even if there is a possibility of a terrorist attack, she cannot violate privacy without a court order". These two replies exemplify the difference between the two subgroups. The group as a whole seemed to be divided among the importance of privacy vis a vis terrorist attack. However, security was slightly more considered than privacy as a diriment value. 